\title{
Utilization of Renal Mass Biopsy in Patients with Renal Cell Carcinoma
}

\author{
John T. Leppert, MD, MS ${ }^{1,2}$, Janet Hanley, MS $^{3}$, Todd H. Wagner, PhD ${ }^{2,4}$, Benjamin I. \\ Chung, MD ${ }^{1}$, Sandy Srinivas, MD ${ }^{5}$, Glenn M. Chertow, MD, MPH ${ }^{5}$, James D. Brooks, MD ${ }^{1}$, \\ Christopher S. Saigal, MD, MPH ${ }^{6}$, and The Urologic Diseases in America Project \\ ${ }^{1}$ Department of Urology, Stanford University School of Medicine, Stanford, CA \\ ${ }^{2}$ Veterans Affairs Palo Alto Healthcare System, Palo Alto, CA \\ ${ }^{3}$ Rand Corporation, Santa Monica, CA \\ ${ }^{4}$ Department of Health Research and Policy, Stanford University School of Medicine, Stanford, \\ CA \\ ${ }^{5}$ Department of Medicine, Stanford University School of Medicine, Stanford, CA \\ ${ }^{6}$ Departments of Urology and Health Services, UCLA School of Medicine, Los Angeles, CA
}

\begin{abstract}
Objectives-To examine the patient, tumor, and temporal factors associated with receipt of RMB in a contemporary nationally representative sample.
\end{abstract}

Methods-We queried the Surveillance, Epidemiology, and End Results-Medicare dataset for incident cases of RCC diagnosed between 1992 and 2007. We tested for associations among receipt of RMB and patient and tumor characteristics, type of therapy, and procedure type. Temporal trends in receipt of RMB were characterized over the study period.

Results-Approximately one in five (20.7\%) patients diagnosed with RCC ( $\mathrm{n}=24,702)$ underwent RMB before instituting therapy. There was a steady and modest increase in RMB utilization, with the highest utilization (30\%) occurring in the final study year. Among patients who underwent radical $(\mathrm{n}=15,666)$ or partial $(\mathrm{n}=2,211)$ nephrectomy, $17 \%$ and $20 \%$, respectively, underwent RMB in advance of surgery. Sixty-five percent of patients who underwent ablation $(\mathrm{n}=314)$ underwent RMB before or in conjunction with the procedure. Roughly half of patients $(50.4 \%)$ treated with systemic therapy alone underwent RMB. Factors independently associated with use of RMB included younger age, black race, Hispanic ethnicity, tumor size $<7 \mathrm{~cm}$, and metastatic disease at presentation.

Conclusions-At present, most patients who eventually undergo radical or partial nephrectomy do not undergo RMB, whereas most patients who eventually undergo ablation or systemic therapy do. The optimal use of RMB in the evaluation of kidney tumors has yet to be determined.

\section{Keywords}

kidney neoplasms; kidney neoplasms epidemiology; kidney neoplasms diagnosis; biopsy

Corresponding author: John T. Leppert, MD MS, Grant S-287, 300 Pasteur Road, Stanford, CA 94305, jleppert@ stanford.edu. Publisher's Disclaimer: This is a PDF file of an unedited manuscript that has been accepted for publication. As a service to our customers we are providing this early version of the manuscript. The manuscript will undergo copyediting, typesetting, and review of the resulting proof before it is published in its final citable form. Please note that during the production process errors may be discovered which could affect the content, and all legal disclaimers that apply to the journal pertain. 


\section{Introduction}

Renal cell carcinoma (RCC, kidney cancer) is one of the most commonly diagnosed cancers ( $6^{\text {th }}$ in men and $8^{\text {th }}$ in women) and is responsible for $3-5 \%$ of all new cancer diagnosis. ${ }^{1}$ In the United States (US) in 2013, it is estimated that 65,150 patients will be diagnosed with kidney or renal pelvis cancer, and that kidney or renal pelvis cancer will be responsible for 13,680 deaths. ${ }^{1}$ Data from the Surveillance, Epidemiology, and End Results (SEER) program of the National Cancer Institute illustrate the steady rise of kidney cancer incidence over the past 30 years, and kidney cancer was recently highlighted as one of seven major malignancies with a rising incidence in the US. ${ }^{2}$ Treatment options for patients with kidney cancer have evolved in parallel with its changing natural history. As kidney cancer is more commonly diagnosed at earlier stages, the number of surgeries for small tumors (benign and malignant) has mirrored the rise in incidence of small tumors such that kidney cancer surgery is now most commonly performed for tumors less than $7 \mathrm{~cm}$ in diameter. ${ }^{3}$

Furthermore, treatment options for localized kidney cancer are expanding, and now include laparoscopic or robotic-assisted partial nephrectomy, percutaneous or laparoscopic thermal ablation, and surveillance. For patients with metastatic kidney cancer, novel targeted therapeutics have been recently approved and are rapidly supplanting immunotherapy for systemic disease.

Renal mass biopsy (RMB) may play an important role in the evaluation of renal masses, the diagnosis of RCC, and the selection of appropriate treatments for individual patients. In specific clinical settings, RMB has shown the potential to identify; 1) benign lesions that do not require surgical intervention, 2) indolent low-risk cancers appropriate for surveillance regimens, 3) intermediate- and high-risk tumors best treated with surgical extirpation, and 4) to provide tissue for histologic diagnosis and molecular biomarkers to guide the selection of targeted therapeutics for advanced disease. ${ }^{4-7}$ In these cases, RMB may reduce the morbidity of unnecessary or futile procedures or treatments and maximize treatment effectiveness. Despite its promise, and published reports demonstrating a favorable safety profile (reviewed in ref. ${ }^{6,8}$ ), historical concerns over the safety and accuracy of RMB have limited its use. Potential complications from RMB include hemorrhage, pneumothorax and seeding of the biopsy tract. The utility of RMB could be limited by targeting or tissue sampling failure, and indeterminate or inaccurate results. ${ }^{9}$

Recent kidney cancer guidelines suggest an increasing role for RMB. ${ }^{10-13}$ The optimal use of RMB is not yet defined and little is known about the current utilization of RMB. We hypothesized that utilization of RMB is increasing and sought to characterize patient and tumor factors associated with its use.

\section{Materials and Methods}

\section{Analytic Cohort}

We queried the National Cancer Institute's Surveillance, Epidemiology, and End Results (SEER) program linked with data from the Centers for Medicare and Medicaid Services (CMS) to identify a population-based cohort of patients with incident RCC diagnosed from 1992 to 2007. Kidney cancer cases were identified from the SEER registry using the International Classification of Disease for Oncology (ICDO) site code (C64.9), and histology codes $(8032,8041,8140,8240,8260,8270,8290,8310,8312,8317,8318,8319$, $8320,8960,8963$, and 8966) were used to select incident non-urothelial carcinoma cases. The cohort was further restricted to those with at least one year of continuous enrollment in CMS services prior to the date of kidney cancer diagnosis in order to have sufficient time to capture comorbid conditions from claims. We excluded patients with pre-existing end-stage 
renal disease based on Medicare disability information as renal biopsy utilization may differ in patients with chronic kidney disease.

\section{Patient Characteristics}

We ascertained demographic data using the SEER dataset (PEDSF file) including age at diagnosis, year of diagnosis, sex, race/ethnicity (White, non-Hispanic, African-American, Hispanic, and other), SEER registry site, US census region, and marital status. We assigned median Census-tract income and Census-tract percentage of high school graduates as patient-level measures of income and education, respectively. Patient comorbidities were ascertained using the Klabunde et al. modification of the Charlson Index derived from claims data submitted during a 12-month period prior to the date of kidney cancer diagnosis using the rule out method described previously. ${ }^{14,15}$

\section{Tumor Characteristics and Treatment Definitions}

Tumor characteristics (stage, size, and histology) were abstracted from SEER registry data. Treatment was defined using mutually exclusive categories based on CMS claims data. Patients were assigned to the surgical treatment category if Current Procedure Terminology (CPT) codes for radical nephrectomy $(50220,50225,50230,50545,50546)$, partial nephrectomy $(50240,50543)$, or laparoscopic or percutaneous ablations $(50250,50542$, $50592,50593,53899,77013,76940,77022)$ were identified. For patients with multiple surgical procedure claims, the first procedure performed was used. When multiple procedure codes were recorded on the same day, we assigned patients to the procedure that was most invasive (radical nephrectomy > partial nephrectomy > ablation). Patients were assigned to the systemic therapy group if CPT codes or J codes for immunotherapy (J9014, J9015, 96409, 96372, 96401) or targeted therapy were identified (J9035, J8999, J9330, C9399, $96413,96415,96372,96401)$. If patients had both systemic therapy and procedure claims, we assigned the patients to the systemic therapy group. If no claims for surgery or systemic therapy were identified within 12 months of the date of diagnosis, the patient was assigned to the no treatment group.

\section{Renal Mass Biopsy and Metastatic Site Biopsy Definitions}

Receipt of a RMB or metastatic site biopsy was determined using claims data in the 12 months preceding the date of diagnosis through the date of treatment or 12 months after the date of diagnosis, whichever came first. Receipt of RMB was identified using CPT codes for image guidance and biopsy procedures; 50200 (renal biopsy), 77012 (CT guidance), 77021 (MRI guidance), and 76942 (ultrasound guidance). Metastatic site biopsies were determined using CPT codes for image guidance $(76942,77002,77003,77012,77021)$ in combination with site-specific biopsy or fine-needle aspiration CPT codes (20206, 20220, 20225, 32400, $32405,38505,47000,47001,48102,49180,60100,10022)$.

\section{Data Analysis}

We examined temporal trends in RMB utilization by comparing the unadjusted annual incidence rates over time. We examined associations among patient and tumor variables and receipt of RMB using Student's t-test for continuous and the $\chi^{2}$ test for categorical variables. We fitted multivariable logistic regression models to estimate the adjusted odds of each patient and tumor characteristic with receipt of RMB. We considered inference tests with 2tailed p-values $<0.05$ to be statistically significant. We conducted analyses using SAS 9.3 (Cary, NC, USA). 


\section{Results}

We identified 24,702 patients diagnosed with kidney cancer between the years 1992 and 2007. Renal mass biopsy (RMB) was performed in 5112 patients, or $20.7 \%$ of the total cohort. Rates of RMB varied by patient factors and are listed in Table 1. Male patients, Hispanic whites and Black patients, and patients with comorbidity (Charlson Comorbidity index score >1) were significantly more likely to undergo RMB. The likelihood of RMB did not differ significantly by geographic region.

Tumor and treatment characteristics associated with RMB are listed in Table 2. Patients with distant (metastatic) disease at diagnosis $(n=1,506,30.5 \%)$ were noted to have higher rates of RMB, as were patients with the smallest tumors $(<4 \mathrm{~cm})(\mathrm{n}=1,673,21.2 \%)$ who were also more likely to have undergone RMB. Patients treated with systemic therapy $(\mathrm{n}=201,50.4 \%)$ and those undergoing ablative procedures $(\mathrm{n}=193,61.5 \%)$ had higher rates of RMB than patients who underwent partial $(\mathrm{n}=452,20.4 \%)$ or radical nephrectomy $(\mathrm{n}=2,702,17.3 \%)$. We identified metastatic site biopsy procedures in $42.1 \%$ of patients treated with systemic therapy that did not undergo RMB.

Temporal trends in utilization of RMB are shown in Figure 1. There was a steady increase in the RMB rates over the study cohort with the highest rate (30.3\%) seen in 2007. In the subgroup of patients with distant disease at presentation there was a rapid rise in RMB rates over the final three study years (2005-2007), coincident with the introduction of newly FDA-approved targeted therapeutics.

Table 3 lists the multivariable logistic regression model and covariates associated with receipt of RMB. As suggested by the temporal trends in RMB, the year of diagnosis was associated with increasing odds of receipt of a RMB. Additional independent factors associated with increased odds of receipt of RMB included younger age, male sex, Black and Hispanic race/ethnicity, tumors $<7 \mathrm{~cm}$ in size, and higher Charlson index scores.

\section{Discussion}

This study of the utilization of RMB yielded several important findings. First, roughly one in five patients diagnosed with kidney cancer undergo biopsy in advance or in conjunction with his or her treatment regimen. There is a growing body of literature documenting the safety, efficacy, accuracy, ${ }^{6,16-21}$ and cost-effectiveness ${ }^{22}$ of RMB. Urology clinical practice guidelines have also suggested a role for RMB in the evaluation of patients with a renal mass. ${ }^{10-13}$ Two systematic reviews of RMB reports demonstrated the safety of modern RMB and its ability to provide diagnostic information. ${ }^{6,8} \mathrm{~A}$ recent report has demonstrated how some institutions have begun incorporating "routine" RMB into the care of patients with kidney cancer. ${ }^{7}$ Despite these guidelines and reports, historical concerns about the efficacy and safety of RMB may still influence the decision of whether or not to proceed with RMB. Until recently, expert opinion argued against routine use of renal biopsy. ${ }^{23}$ RMB rates are noticeably lower among patients with small kidney cancers and patients who did not undergo treatment within one year of diagnosis. The implication of these findings is that RMB is not part of routine community practice for selecting surgical treatments, or for identifying patients appropriate for surveillance.

Second, over the study period there was a modest but steady rise in RMB rates, with the highest rates in the final study year. Our multivariable analysis identified a small but significant increase in RMB utilization by study year (OR 1.04, 95\% CI 1.03-1.05) after adjusting for patient (age, sex, race) and tumor factors (size, stage). The increasing utilization of RMB may be partially explained by two groups; patients with distant disease and patients with small kidney cancers treated with ablative procedures. The introduction of 
multiple novel therapies since 2006 has changed the treatment paradigm for patients with metastatic disease. Previously, patients with distant disease were primarily selected for systemic immunotherapy based on their performance status and the histology identified by cytoreductive nephrectomy. In future precision medicine models, RMB may identify the specific molecular pathway alterations in the tumor, guiding the selection of targeted therapy while obviating the need for surgery. While more than $50 \%$ of patients treated with systemic therapy received RMB, we noted that $30 \%$ of patients treated with systemic therapy and surgery received RMB. This discrepancy may be explained in part by those patients that undergo cytoreductive nephrectomy procedures. Nearly $29 \%$ of patients treated with systemic therapy did not have a claim for RMB or biopsy of a metastatic site to provide histologic confirmation of kidney cancer and may include patients who are treated without microscopic confirmation. With the introduction of additional targeted agents, and the diffusion of these and other new drugs into community-based practice, it is likely that utilization of RMB will continue to increase in this patient group.

RMB utilization was also high among patients with relatively small tumors who were treated with ablative procedures. Tumor ablation procedures, such as radio frequency ablation and cryotherapy, involve placement of a needle into the tumor for treatment, and are considered acceptable treatment for patients with low-risk disease or those that are not considered surgical candidates. ${ }^{11,12}$ Since image guided needle placement is a part of these procedures, it is logical to perform a RMB at the time of the procedure to confirm that the lesion is malignant. In fact, guidelines suggest that RMB should be performed in all patients undergoing ablative therapy for this reason. ${ }^{13}$ While $61.5 \%$ of patients treated with ablative procedures underwent RMB, $39.5 \%$ did not. Since few patients can have reliable determination of pathological changes after ablation, care providers should recognize uncertainties when proceeding with ablation in the absence of RMB. Finally, there are disparities in the utilization of RMB. While considerations for RMB are understandable based on age and comorbidities, it is interesting that RMB utilization differed by sex and race. Male patients with kidney cancer were more likely to have received a RMB, as were Black and Hispanic patients. Differential use of RMB among minorities persisted after adjustment for age at diagnosis, comorbidity and tumor size. Reasons for this disparity are unknown, but warrant more focused attention.

Our study has several important limitations. Administrative (SEER) and claims based (Medicare) data suffer from missing data, and issues related to data quality have been previously observed. In additional, our study was limited to patients older than 66 years of age and may not reflect practice patterns for younger patients, those with private insurance, or cash-paying patients. We were not able to investigate the associations among provider characteristics or treatment facility type on RMB rates, many of which could influence utilization of diagnostic RMB in patients with suspected or diagnosed kidney cancer. Patient factors and preferences were not measured in this study, and may also influence the likelihood of pursuing diagnostic biopsy, particularly in the face of fears of metastatic seeding. Noteably, our denominator is the number of patients with diagnosed kidney cancer and not the total number of patients who underwent RMB. Therefor, we have no data on the disposition of patients with suspected kidney cancer who underwent RMB and had negative or indeterminate results, or data on patients who may have had suspected kidney cancer, but the diagnosis was not confirmed either by RMB or surgical excision. Finally, we had no data on performance characteristics (i.e., sensitivity, specificity, positive and negative predictive values) of RMB in this population, so we could not reach any inferences on the use of the procedure in the diagnostic algorithm of a new renal mass. Despite these limitations, this descriptive analysis of the utilization of the RMB will set the stage for future investigation of the effectiveness of RMB, and strategies for implementing RMB in the evaluation of patients with a renal mass. 


\section{Conclusions}

Relatively few patients with kidney cancer receive a RMB, despite availability of newer therapies that might benefit from histologic diagnosis prior to treatment selection. The rates of RMB have gradually increased over time, but the patterns of utilization show differential application based on age, sex, race/ethnicity and several clinical characteristics. The optimal use of RMB in the evaluation of kidney tumors has yet to be determined.

\section{Acknowledgments}

The Urologic Diseases in America Project is sponsored by a grant from the National Institute of Diabetes and Digestive and Kidney Diseases (NIDDK), National Institutes of Health (NIH). Dr. Leppert is supported by K23 DK089086. Dr. Chertow is supported by K24 DK085446. The content is solely the responsibility of the authors and does not necessarily represent the official view of the NIH/NIDDK.

\section{References}

1. Siegel R, Naishadham D, Jemal A. Cancer statistics, 2013. CA Cancer J Clin. 2013; 63:11-30. [PubMed: 23335087]

2. Simard EP, Ward EM, Siegel R, Jemal A. Cancers with increasing incidence trends in the United States: 1999 through 2008. CA Cancer J Clin. 2012:118-28.

3. Hollingsworth JM, Miller DC, Daignault S, Hollenbeck BK. Rising incidence of small renal masses: a need to reassess treatment effect. J Natl Cancer Inst. 2006; 98:1331-4. [PubMed: 16985252]

4. Mally AD, Gayed B, Averch T, Davies B. The current role of percutaneous biopsy of renal masses. Can J Urol. 2012; 19:6243-9. [PubMed: 22704306]

5. Menogue SR, O'Brien BA, Brown AL, Cohen RJ. Percutaneous core biopsy of small renal mass lesions: a diagnostic tool to better stratify patients for surgical intervention. BJU Int. 2013; 111:E146-51. [PubMed: 22805186]

6. Volpe A, Finelli A, Gill IS, Jewett MA, Martignoni G, Polascik TJ, Remzi M, Uzzo RG. Rationale for percutaneous biopsy and histologic characterisation of renal tumours. Eur Urol. 2012; 62:491504. [PubMed: 22633318]

7. Halverson SJ, Kunju LP, Bhalla R, Gadzinski AJ, Alderman M, Miller DC, Montgomery JS, Weizer $\mathrm{AZ}, \mathrm{Wu} \mathrm{A}, \mathrm{Hafez} \mathrm{KS}$, et al. Accuracy of determining small renal mass management with risk stratified biopsies: confirmation by final pathology. J Urol. 2013; 189:441-6. [PubMed: 23253955]

8. Lane BR, Samplaski MK, Herts BR, Zhou M, Novick AC, Campbell SC. Renal mass biopsy--a renaissance? J Urol. 2008; 179:20-7. [PubMed: 17997455]

9. Lane BR, Samplaski MK, Herts BR, Zhou M, Novick AC, Campbell SC. Renal mass biopsy--a renaissance? The Journal of urology. 2008; 179:20-7. [PubMed: 17997455]

10. Ljungberg B, Cowan NC, Hanbury DC, Hora M, Kuczyk MA, Merseburger AS, Patard JJ, Mulders PF, Sinescu IC. European Association of Urology Guideline G. EAU guidelines on renal cell carcinoma: the 2010 update. Eur Urol. 2010; 58:398-406. [PubMed: 20633979]

11. Campbell SC, Novick AC, Belldegrun A, Blute ML, Chow GK, Derweesh IH, Faraday MM, Kaouk JH, Leveillee RJ, Matin SF, et al. Guideline for management of the clinical T1 renal mass. J Urol. 2009; 182:1271-9. [PubMed: 19683266]

12. Motzer RJ, Agarwal N, Beard C, Bolger GB, Boston B, Carducci MA, Choueiri TK, Figlin RA, Fishman M, Hancock SL, et al. NCCN clinical practice guidelines in oncology: kidney cancer. J Natl Compr Canc Netw. 2009; 7:618-30. [PubMed: 19555584]

13. Escudier B, Eisen T, Porta C, Patard JJ, Khoo V, Algaba F, Mulders P, Kataja V. Group EGW. Renal cell carcinoma: ESMO Clinical Practice Guidelines for diagnosis, treatment and follow-up. Ann Oncol. 2012; 23(Suppl 7):vii65-71. [PubMed: 22997456]

14. Charlson ME, Pompei P, Ales KL, MacKenzie CR. A new method of classifying prognostic comorbidity in longitudinal studies: development and validation. J Chronic Dis. 1987; 40:373-83. [PubMed: 3558716]

15. Klabunde CN, Potosky AL, Legler JM, Warren JL. Development of a comorbidity index using physician claims data. J Clin Epidemiol. 2000; 53:1258-67. [PubMed: 11146273] 
16. Veltri A, Garetto I, Tosetti I, Busso M, Volpe A, Pacchioni D, Bollito E, Papotti M. Diagnostic accuracy and clinical impact of imaging-guided needle biopsy of renal masses. Retrospective analysis on 150 cases. Eur Radiol. 2011; 21:393-401. [PubMed: 20809129]

17. Leveridge MJ, Finelli A, Kachura JR, Evans A, Chung H, Shiff DA, Fernandes K, Jewett MA. Outcomes of small renal mass needle core biopsy, nondiagnostic percutaneous biopsy, and the role of repeat biopsy. Eur Urol. 2011; 60:578-84. [PubMed: 21704449]

18. Lebret T, Poulain JE, Molinie V, Herve JM, Denoux Y, Guth A, Scherrer A, Botto H. Percutaneous core biopsy for renal masses: indications, accuracy and results. J Urol. 2007; 178:1184-8. discussion 1188. [PubMed: 17698122]

19. Menogue SR, O’Brien BA, Brown AL, Cohen RJ. Percutaneous core biopsy of small renal mass lesions: a diagnostic tool to better stratify patients for surgical intervention. BJU Int. 2012

20. Pandharipande PV, Gervais DA, Hartman RI, Harisinghani MG, Feldman AS, Mueller PR, Gazelle GS. Renal mass biopsy to guide treatment decisions for small incidental renal tumors: a costeffectiveness analysis. Radiology. 2010; 256:836-46. [PubMed: 20720070]

21. Volpe A, Kachura JR, Geddie WR, Evans AJ, Gharajeh A, Saravanan A, Jewett MA. Techniques, safety and accuracy of sampling of renal tumors by fine needle aspiration and core biopsy. J Urol. 2007; 178:379-86. [PubMed: 17561170]

22. Heilbrun ME, Yu J, Smith KJ, Dechet CB, Zagoria RJ, Roberts MS. The cost-effectiveness of immediate treatment, percutaneous biopsy and active surveillance for the diagnosis of the small solid renal mass: evidence from a Markov model. J Urol. 2012; 187:39-43. [PubMed: 22088331]

23. Campbell, MF.; Walsh, PC.; Retik, AB. Campbell's urology. Philadelphia, PA: Saunders; 2002. p. $4 \mathrm{v}(\mathrm{xl}, 3954,128 \mathrm{p}$. 


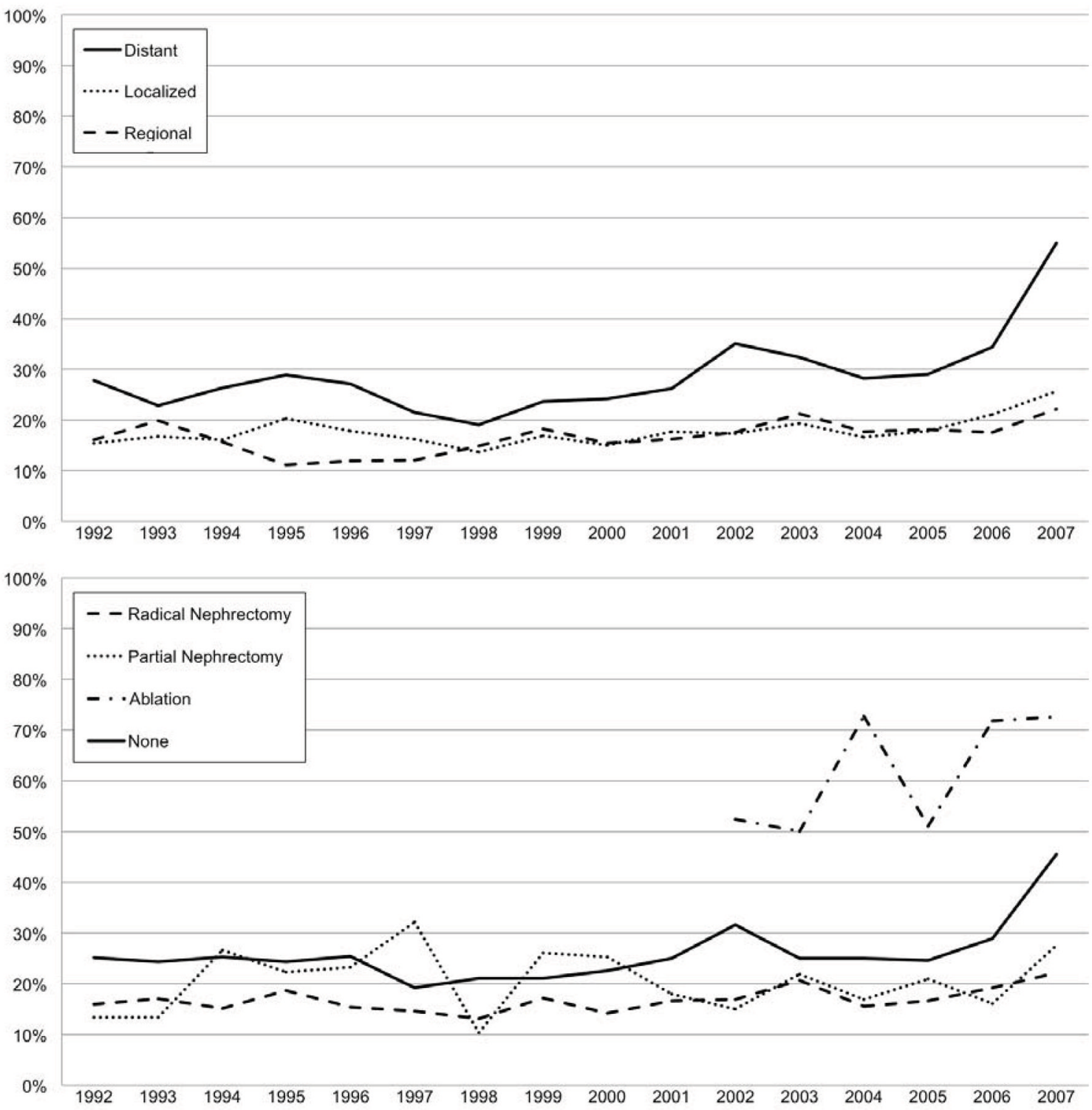

Figure 1.

Temporal trends in renal mass biopsy utilization (1992-2007). The top panel represents the utilization of renal mass biopsy by stage at diagnosis. The bottom panel represents the utilization of renal mass biopsy stratified by the type of surgical therapy (if any). 
Table 1

Patient characteristics of RCC patients by receipt of renal mass biopsy.

\begin{tabular}{|c|c|c|c|}
\hline Characteristic & RMB + & RMB - & $\chi^{2} \mathbf{P}$ value \\
\hline No. Patients (\%): & $5,112(20.7)$ & $19,590(79.3)$ & \\
\hline \multicolumn{4}{|l|}{ Age Group (\%): } \\
\hline $66-69$ & $1,091(21.3)$ & $4,127(21.1)$ & $\mathrm{P}=0.0038$ \\
\hline $70-74$ & $1,450(28.4)$ & $5,483(28.0)$ & \\
\hline $75-79$ & $1,366(26.7)$ & $4,907(25.1)$ & \\
\hline$\geq 80$ & $1,205(23.6)$ & $5,073(25.9)$ & \\
\hline \multicolumn{4}{|l|}{$\operatorname{Sex}(\%)$} \\
\hline Male & $3,346(65.5)$ & $11,118(56.8)$ & $\mathrm{P}<0.0001$ \\
\hline Female & $1,766(34.6)$ & $8,472(43.3)$ & \\
\hline \multicolumn{4}{|l|}{ Race/Ethnicity (\%): } \\
\hline White, non-Hispanic & $4,171(81.6)$ & $16,335(83.4)$ & $\mathrm{P}=0.0004$ \\
\hline White, Hispanic & $330(6.5)$ & $1,091(5.6)$ & \\
\hline Black & $440(8.6)$ & $1,429(7.3)$ & \\
\hline Other or Unknown Race & $171(3.6)$ & $735(3.8)$ & \\
\hline \multicolumn{4}{|l|}{ Marital Status (\%): } \\
\hline Single & $353(6.9)$ & $1,290(6.6)$ & $\mathrm{P}=0.0008$ \\
\hline Married & 3,147 (61.6) & $11,578(59.1)$ & \\
\hline Divorced/Widowed & $1,434(28.1)$ & $6,075(31.0)$ & \\
\hline Unknown & $178(3.5)$ & $647(3.3)$ & \\
\hline \multicolumn{4}{|l|}{ Charlson Index Score: } \\
\hline 0 & $3,091(60.5)$ & $12,593(64.3)$ & $\mathrm{P}<0.0001$ \\
\hline 1 & $1,192(23.3)$ & $4,310(22.0)$ & \\
\hline$\geq 2$ & $829(16.2)$ & $2,687(13.7)$ & \\
\hline \multicolumn{4}{|l|}{ US Census Region (\%): } \\
\hline Midwest & $1,086(21.2)$ & $4,168(21.3)$ & $\mathrm{P}=0.23$ \\
\hline Northeast & $1,016(19.9)$ & $4,119(21.0)$ & \\
\hline South & $820(16.0)$ & $3,169(16.2)$ & \\
\hline West & $2,190(42.8)$ & $8,134(41.5)$ & \\
\hline \multicolumn{4}{|c|}{ Median census tract income in $\$(\%)$ : } \\
\hline$\leq 35,000$ & $1,092(26.6)$ & $4,031(25.8)$ & $\mathrm{P}=0.044$ \\
\hline $35,000-44,999$ & $898(21.9)$ & $3,535(22.7)$ & \\
\hline $45,000-59,999$ & $1,065(26.0)$ & $3,806(24.4)$ & \\
\hline$\geq 60,000$ & $1,047(25.5)$ & $4,237(27.1)$ & \\
\hline \multicolumn{4}{|c|}{ Census tract $\%$ high school graduation $(\%)$ : } \\
\hline$\unlhd 0$ & $1,152(28.1)$ & $4,585(29.4)$ & $\mathrm{P}=0.10$ \\
\hline $10-15$ & $822(20.0)$ & $3,226(20.7)$ & \\
\hline $15-25$ & $1,055(25.7)$ & $3,977(25.5)$ & \\
\hline$\geq 25$ & $1,073(26.2)$ & $3,821(24.5)$ & \\
\hline
\end{tabular}

Urology. Author manuscript; available in PMC 2015 April 01. 
Table 2

Tumor and treatment characteristics of RCC patients by receipt of renal mass biopsy.

\begin{tabular}{|c|c|c|c|}
\hline Characteristic & RMB + & RMB - & $\chi^{2} \mathbf{P}$ value \\
\hline \multicolumn{4}{|l|}{ Tumor Size $(\mathrm{cm})$ : } \\
\hline No mass & $3(0.1)$ & $7(0.0)$ & $\mathrm{P}<0.0001$ \\
\hline$\leq 4$ & $1,673(32.7)$ & $6,235(31.8)$ & \\
\hline $4-7$ & $1,452(28.4)$ & $6,297(32.1)$ & \\
\hline $7-10$ & $917(17.9)$ & $3,766(19.2)$ & \\
\hline$\geq 10$ & 437 (8.6) & $1,694(8.7)$ & \\
\hline Unknown & $630(12.3)$ & $1,591(8.1)$ & \\
\hline \multicolumn{4}{|l|}{ Tumor Stage: } \\
\hline Localized & $2,804(54.9)$ & $12,318(62.9)$ & $\mathrm{P}<0.0001$ \\
\hline Regional & $802(15.7)$ & $3,842(19.6)$ & \\
\hline Distant & $1,506(29.5)$ & $3,430(17.5)$ & \\
\hline \multicolumn{4}{|l|}{ Treatment Type: } \\
\hline Surgery & $3,192(62.4)$ & $14,489(74.0)$ & $\mathrm{P}<0.0001$ \\
\hline Systemic Therapy & $201(3.9)$ & $198(1.0)$ & \\
\hline Systemic Therapy + Surgery & $155(3.0)$ & $355(1.8)$ & \\
\hline None & $1,564(30.6)$ & $4,548(23.2)$ & \\
\hline \multicolumn{4}{|l|}{ Surgical Type: } \\
\hline Radical nephrectomy & $2,702(52.9)$ & $12,964(66.2)$ & $\mathrm{P}<0.0001$ \\
\hline Partial nephrectomy & $452(8.8)$ & $1,759(9.0)$ & \\
\hline Ablation & $193(3.8)$ & $121(0.6)$ & \\
\hline None & $1,765(34.5)$ & $4,746(24.2)$ & \\
\hline
\end{tabular}

Urology. Author manuscript; available in PMC 2015 April 01. 


\section{Table 3}

Multivariable model reporting the odds ratios of receipt of renal mass biopsy when adjusted for the listed patient and tumor factors.

\begin{tabular}{ll}
\hline Characteristic & Odds Ratio $(\mathbf{9 5 \%}$ CI) \\
\hline Age (per 10 year increase) & $\mathbf{0 . 8 8}(\mathbf{0 . 8 4 - 0 . 9 3})$ \\
Sex (Male $v s$. Female) & $\mathbf{1 . 4 4}(\mathbf{1 . 2 3}-\mathbf{1 . 5 4})$ \\
Year & $\mathbf{1 . 0 4}(\mathbf{1 . 0 3 - 1 . 0 5 )}$ \\
Charlson Index Score: & \\
$1-2$ vs. 0 & $\mathbf{1 . 1 4}(\mathbf{1 . 0 6 - 1 . 2 2})$ \\
3 vs. 0 & $\mathbf{1 . 3 8}(\mathbf{1 . 2 2}-\mathbf{1 . 5 7})$ \\
Race: & \\
Black $v s$. White & $\mathbf{1 . 2 0}(\mathbf{1 . 0 7 - 1 . 3 5})$ \\
Hispanic $v s$. White & $\mathbf{1 . 1 5}(\mathbf{1 . 0 1 - 1 . 3 1})$ \\
Other race $v s$. White & $0.88(0.74-1.04)$ \\
Married & $1.01(0.94-1.08)$ \\
Tumor Stage: & \\
Regional $v s$. Localized & $0.98(0.90-1.08)$ \\
Metastatic $v s$. Localized & $\mathbf{2 . 1 2}(\mathbf{1 . 9 7}-\mathbf{2 . 2 9})$ \\
Tumor Size $27 \mathrm{~cm}$ & $\mathbf{0 . 8 5}(\mathbf{0 . 7 9 - 0 . 9 1 )}$ \\
\hline
\end{tabular}

Odds Ratios in bold when meeting 0.05 statistical significance level. 